\title{
How many people would benefit from a smart wheelchair?
}

\author{
Richard C. Simpson, PhD, ATP; ${ }^{1-2 *}$ Edmund F. LoPresti, PhD; ${ }^{3}$ Rory A. Cooper, PhD ${ }^{1-2}$ \\ ${ }^{1}$ Department of Rehabilitation Sciences and Technology, University of Pittsburgh, Pittsburgh, PA; ${ }^{2}$ Human Engineering \\ Research Laboratories, Department of Veterans Affairs Pittsburgh Healthcare System, Pittsburgh, PA; ${ }^{3}$ AT Sciences, \\ Pittsburgh, PA
}

\begin{abstract}
Independent mobility is important, but some wheelchair users find operating existing manual or powered wheelchairs difficult or impossible. Challenges to safe, independent wheelchair use can result from various overlapping physical, perceptual, or cognitive symptoms of diagnoses such as spinal cord injury, cerebrovascular accident, multiple sclerosis, amyotrophic lateral sclerosis, and cerebral palsy. Persons with different symptom combinations can benefit from different types of assistance from a smart wheelchair and different wheelchair form factors. The sizes of these user populations have been estimated based on published estimates of the number of individuals with each of several diseases who (1) also need a wheeled mobility device and (2) have specific symptoms that could interfere with mobility device use.
\end{abstract}

Key words: assistive technology, cognitive impairment, humanmachine systems, physical impairment, rehabilitation, robotics, smart wheelchairs, wheelchairs, wheeled mobility, veterans, visual impairment.

\section{INTRODUCTION}

Several studies have shown that both children and adults benefit substantially from access to independent mobility [1-3]. Independent mobility increases vocational and educational opportunities, reduces dependence on caregivers and family members, and promotes feelings of self-reliance. Reductions in functional mobility are linked with reduced participation and loss of social connections [4]. Psychologically, decreases in mobility can lead to feelings of emotional loss, reduced self-esteem, isolation, stress, and fear of abandonment [4].
For adults, independent mobility plays a pivotal role in “aging in place.” If adults become unable to walk or wheel themselves independently and help is routinely unavailable in the home when needed, moving to a more supportive environment (e.g., assisted living) is often necessary. Mobility limitations are the leading cause of functional limitations among adults with an estimated prevalence of 40 per 1,000 persons aged 18 to 44 and 188 per 1,000 aged 85 years and older in the general population [5]. Mobility difficulties are also strong predictors of difficulties with activities of daily living (ADL) and instrumental ADL, because individuals need to move to accomplish many of these activities. In addition, impaired mobility often decreases the opportunity to socialize, which results in social isolation, anxiety, and depression [6].

\footnotetext{
Abbreviations: $\mathrm{AD}=$ Alzheimer disease; $\mathrm{ADL}=$ activities of daily living; AIS = Abbreviated Injury Scale; ALS = amyotrophic lateral sclerosis; ATRS = Automated Transport and Retrieval System; C4 = fourth cervical vertebra; $\mathrm{CNS}$ = central nervous system; $\mathrm{CP}$ = cerebral palsy; $\mathrm{CVA}=$ cerebrovascular accident; GCS = Glasgow Coma Scale; ICF = International Classification of Functioning, Disability and Health; MS = multiple sclerosis; MSA = multiple system atrophy; PD = Parkinson disease; $\mathrm{PSP}=$ progressive supranuclear palsy; $\mathrm{SCI}=$ spinal cord injury; TBI = traumatic brain injury.

*Address all correspondence to Richard C. Simpson, PhD, ATP; Department of Rehabilitation Sciences and Technology, University of Pittsburgh, Forbes Tower, Suite 5044, Pittsburgh, PA 15238-2887; 412-383-6593; fax: 412-3836597. Email: $\underline{\text { ris20@pitt.edu }}$
}

DOI: 10.1682/JRRD.2007.01.0015 
Traditional manual wheelchairs provide mobility to individuals with physical impairments but are poorly suited for individuals with a combination of physical and cognitive or perceptual impairments. Manual wheelchairs are more physically demanding than powered wheelchairs; however, powered wheelchairs require cognitive and physical skills that not all individuals possess. For example, a survey of 65 practicing clinicians in a variety of rehabilitation services from 29 states reported that between 10 and 40 percent of their clients who desired powered mobility could not be fitted with powered wheelchairs because sensory impairments, poor motor function, or cognitive deficits made driving safely impossible with any of the existing controls [7]. Those individuals who are considered unable to safely and independently operate a manual or powered wheelchair are typically seated in a manual wheelchair and pushed by a caregiver.

To accommodate users who find operating standard mobility devices difficult or impossible, several researchers have used technologies originally developed for mobile robots to create smart wheelchairs [8]. A smart wheelchair typically consists of either a standard powered wheelchair to which a computer and a collection of sensors have been added or a mobile robot base to which a seat has been attached. Smart wheelchairs have been designed that help the user to navigate in a number of different ways, such as assuring collision-free travel, aiding the performance of specific tasks (e.g., passing through doorways), and autonomously transporting the user between locations [8].

Compared with all the effort expended to develop smart wheelchairs, relatively little effort has been devoted to characterize and quantify the need for smart wheelchairs. Defining need, of course, is difficult at best. Even the best wheelchair operators have accidents colliding with obstacles, so defining the need for a smart wheelchair as "may cause harm to someone or something while using their wheelchair" is entirely too broad. Narrowing the definition based on skill (e.g., "is likely to cause harm to something or someone while using their wheelchair") is equally problematic. Neither a widely accepted metric of wheelchair skill nor an agreed-upon "score" exists that can be used as a boundary between "is likely to cause harm" and "is not likely to cause harm." Furthermore, data on wheelchair skill across diagnoses and symptoms simply do not exist.

An alternative approach, adopted here, is to focus on who might benefit from smart wheelchair technology. For this analysis, symptoms that result from specific diagnoses have been matched to capabilities that have been implemented or envisioned for smart wheelchairs. The incidence of the diagnoses and the symptoms associated with the diagnoses have then been used to estimate the number of people who might benefit from various types of smart wheelchair assistance. What emerges, then, is not a single number but several numbers, each associated with a different impairment or type of navigation assistance.

\section{PREVIOUS RESEARCH}

Smart wheelchairs have been researched since the early 1980s and have been developed on four continents [8]. Some smart wheelchairs operate similarly to autonomous robots: the user specifies a final destination and supervises as the smart wheelchair plans and executes a path to the target location. To reach the destination, the systems typically require either a complete map of the area through which they navigate or modifications to their environment (e.g., tape tracks placed on the floor or markers placed on the walls). They are usually unable to compensate for unplanned obstacles or travel in unknown areas. Smart wheelchairs in this group are most appropriate for users who (1) lack the ability to plan and/or execute a path to a destination and (2) spend most of their time within the same controlled environment.

Another group of smart wheelchairs assists only with collision avoidance, and the user has all the duties of planning and navigating. These systems do not normally require an internal map of an area or any specific alterations to the environment. However, they do require more planning and continuous user assistance and are only appropriate for users who can effectively plan and execute a path to a destination. A final group of smart wheelchairs offers both autonomous and semiautonomous navigation.

Smart wheelchairs have also been used to explore a variety of alternatives to the more "traditional" input methods associated with powered wheelchairs (e.g., joystick, pneumatic switches). Automatic speech recognition has often been used for smart wheelchairs, because of the low cost and wide availability of commercial speech recognition hardware and software. More exotic input methods that have been implemented include using electrooculographic activity that detects where the wheelchair user is looking or using machine vision for calculating the position and orientation of the head. 


\section{METHODS}

Research literature was surveyed for epidemiological data on a variety of diagnoses with symptoms that might (1) cause an individual to use a manual or powered wheelchair at least part of the time and (2) interfere with an individual's ability to use a wheelchair safely and independently at least part of the time. In several cases, the percentage of individuals with a specific diagnosis who are using a wheelchair at a single point in time has not been determined. Similarly, the number of individuals with a given diagnosis who use a wheelchair and exhibit a specific symptom is typically not available. In these instances, estimates have been made based on data from reported research. However, one should note that some of the samples involved are small and not all the studies were conducted in the United States. These estimations may have been avoided with the literature search being expanded to include older literature, but this action would have introduced a risk of incorporating data that does not reflect the capabilities of current medical and rehabilitation techniques.

In some cases, two or more estimates for values were available and reported. Where only a single value was found in the literature, we considered this value both the lower bound and the upper bound. In cases where values were provided as a ratio, we calculated an exact number by multiplying the ratio by an estimated U.S. population of 298,000,000 (as of July 2006) [9].

An important assumption made throughout this article is that symptoms are evenly distributed within a diagnosis. In other words, if 25 percent of individuals with a given diagnosis use a wheelchair and 10 percent of individuals with that same diagnosis are reported to have a specific symptom, then 10 percent of the 25 percent of individuals with that diagnosis who use a wheelchair exhibit that symptom. In addition, 10 percent of the 75 percent of individuals with that diagnosis who do not use a wheelchair also exhibit that symptom. Most likely, wheelchair use is associated with a greater incidence of some symptoms, but lacking data to guide estimates to that effect, we considered this approach the most conservative.

Similarly, the most conservative approach to estimating the number of individuals who have a single diagnosis and have any of two or more symptoms is to assume that all individuals with the most common symptom also have all the other symptoms. For example, if 10 percent of individuals with a given diagnosis have symptom A,
15 percent have symptom $B$, and 20 percent have symptom $\mathrm{C}$, then the most conservative estimate of the number of people with that diagnosis who have symptom A, B, or $\mathrm{C}$ is 20 percent.

\section{User Populations and Their Wheelchair Use}

This section discusses diagnoses that are associated with manual or powered wheelchair use. Estimates for prevalence and incidence are provided, along with estimates for the proportion of individuals within each diagnosis who need a wheelchair. In addition, symptoms associated with each diagnosis that might interfere with wheelchair use are discussed. The results of this analysis are summarized in Table $\mathbf{1}$ (discussions concerning blindness and low vision can be found in the "Impairments that Affect Wheeled Mobility” section).

\section{Alzheimer Disease}

Alzheimer disease (AD) results in abnormal protein deposits in the brain, forming amyloidlike filaments [10]. The diagnosis of probable AD is supported by progressive deterioration of functions such as language, motor skills, and perception [11]. As of 1996, AD affected an estimated 4 million people in the United States [11]. The incidence of $\mathrm{AD}$ increases with age, from 4.3 percent of persons in the United States over the age of 75 to 28.5 percent of persons over 90 [12]. In a study of 26 patients diagnosed with AD in Italy, 15 percent had "severe" or “complete" difficulty with walking [13].

\section{Amyotrophic Lateral Sclerosis}

Amyotrophic lateral sclerosis (ALS) is a progressive motor neuron disease resulting in premature degeneration of motor neurons [14]. ALS typically occurs later in life (usually in persons between the ages of 45 and 60) with a typical course of 1 to 5 years [14]. Symptoms of ALS include progressive weakness, atrophy, and spasticity [14]. The muscle weakness associated with ALS can interfere with an individual's ability to operate a wheelchair in two ways: (1) weakness or fatigue in the arms and shoulders can prevent persons from completing long routes and (2) weakness in the neck muscles can make seeing obstacles behind or next to the wheelchair difficult or impossible.

ALS is prevalent in the United States in 25,000 to 30,000 persons [15] and has an annual incidence of 1.4 cases per 100,000 persons [15]. Every person diagnosed with ALS will eventually need a wheelchair. However, 
JRRD, Volume 45, Number 1, 2008

Table 1.

Potential smart wheelchairs users, organized by diagnosis.

\begin{tabular}{|c|c|c|c|c|c|c|c|}
\hline \multirow[b]{2}{*}{ Diagnosis } & \multicolumn{2}{|c|}{ Prevalence } & \multicolumn{2}{|c|}{ \% Need Wheelchair } & \multirow[b]{2}{*}{ Symptom } & \multicolumn{2}{|c|}{ \% with Symptom } \\
\hline & $\begin{array}{c}\text { Lowest } \\
\text { Estimate }\end{array}$ & $\begin{array}{l}\text { Highest } \\
\text { Estimate }\end{array}$ & $\begin{array}{c}\text { Lowest } \\
\text { Estimate }\end{array}$ & $\begin{array}{l}\text { Highest } \\
\text { Estimate }\end{array}$ & & $\begin{array}{c}\text { Lowest } \\
\text { Estimate }\end{array}$ & $\begin{array}{l}\text { Highest } \\
\text { Estimate }\end{array}$ \\
\hline$\overline{\mathrm{AD}}$ & $2,300,000$ & $4,000,000$ & - & 15.0 & $\begin{array}{l}\text { Attention, agitation, \& impulse control } \\
\text { Executive reasoning }\end{array}$ & $\begin{array}{l}48.0 \\
41.0\end{array}$ & $\begin{array}{l}48.0 \\
41.0\end{array}$ \\
\hline ALS & 25,000 & 30,000 & 46.0 & 80.0 & $\begin{array}{l}\text { Fatigue/weakness } \\
\text { Head/neck movement }\end{array}$ & $\begin{array}{l}26.0 \\
26.0\end{array}$ & $\begin{array}{l}26.0 \\
26.0\end{array}$ \\
\hline $\mathrm{CP}$ & 750,000 & 750,000 & - & 86.0 & $\begin{array}{l}\text { Spasticity } \\
\text { Tremor } \\
\text { Hemiplegia } \\
\text { Ataxia } \\
\text { Dystonia } \\
\text { Executive reasoning }\end{array}$ & $\begin{array}{r}70.0 \\
10.0 \\
15.0 \\
5.0 \\
17.6 \\
30.0\end{array}$ & $\begin{array}{l}90.0 \\
20.0 \\
15.0 \\
10.0 \\
17.6 \\
41.0\end{array}$ \\
\hline CVA (right-hemisphere) & $1,200,000$ & $1,200,000$ & 15.0 & 25.0 & $\begin{array}{l}\text { Visual field neglect } \\
\text { Visual field loss } \\
\text { Spasticity } \\
\text { Hemiplegia }\end{array}$ & $\begin{array}{l}13.0 \\
20.0 \\
35.0 \\
50.0\end{array}$ & $\begin{array}{l}82.0 \\
20.0 \\
51.0 \\
50.0\end{array}$ \\
\hline CVA (left-hemisphere) & $1,200,000$ & $1,200,000$ & 15.0 & 25.0 & $\begin{array}{l}\text { Visual field neglect } \\
\text { Visual field loss } \\
\text { Spasticity } \\
\text { Hemiplegia }\end{array}$ & $\begin{array}{r}0.0 \\
20.0 \\
35.0 \\
50.0\end{array}$ & $\begin{array}{l}76.0 \\
20.0 \\
51.0 \\
50.0\end{array}$ \\
\hline Legally Blind & $1,057,389$ & $1,057,389$ & - & 9.6 & Blindness & 100.0 & 100.0 \\
\hline Low Vision & $5,315,541$ & $5,315,541$ & - & 5.3 & Low vision & 100.0 & 100.0 \\
\hline MS & 250,000 & 350,000 & - & 69.0 & $\begin{array}{l}\text { Spasticity } \\
\text { Tremor } \\
\text { Fatigue/weakness } \\
\text { Head/neck movement } \\
\text { Ataxia } \\
\text { Executive reasoning }\end{array}$ & $\begin{array}{r}65.0 \\
6.0 \\
43.0 \\
43.0 \\
23.0 \\
30.0\end{array}$ & $\begin{array}{r}90.0 \\
6.0 \\
90.0 \\
90.0 \\
84.0 \\
70.0\end{array}$ \\
\hline MSA & 5,543 & 14,602 & - & 60.0 & $\begin{array}{l}\text { Nystagmus } \\
\text { Restricted down gaze } \\
\text { Spasticity } \\
\text { Tremor } \\
\text { Ataxia } \\
\text { Bradykinesia } \\
\text { Dystonia } \\
\text { Executive reasoning }\end{array}$ & $\begin{array}{r}10.0 \\
23.0 \\
10.0 \\
52.0 \\
56.0 \\
71.0 \\
31.0 \\
0.5\end{array}$ & $\begin{array}{l}37.0 \\
23.0 \\
10.0 \\
84.3 \\
86.8 \\
97.6 \\
43.0 \\
17.0\end{array}$ \\
\hline PD & 894,000 & 894,000 & - & 10.0 & $\begin{array}{l}\text { Visual field neglect } \\
\text { Tremor } \\
\text { Bradykinesia } \\
\text { Executive reasoning }\end{array}$ & $\begin{array}{l}90.0 \\
63.0 \\
12.5 \\
23.0\end{array}$ & $\begin{array}{l}90.0 \\
63.0 \\
12.5 \\
44.0\end{array}$ \\
\hline PSP & 4,142 & 4,142 & - & 70.0 & $\begin{array}{l}\text { Impaired eye movement } \\
\text { Tremor } \\
\text { Bradykinesia } \\
\text { Executive reasoning }\end{array}$ & $\begin{array}{r}6.0 \\
5.0 \\
22.0 \\
50.0\end{array}$ & $\begin{array}{r}6.0 \\
21.0 \\
91.0 \\
50.0\end{array}$ \\
\hline Severe TBI (AIS 5 or GCS < 9) & 530,000 & 530,000 & - & 9.0 & $\begin{array}{l}\text { Visual field neglect } \\
\text { Hemiplegia } \\
\text { Tremor } \\
\text { Bradykinesia } \\
\text { Fatigue/weakness } \\
\text { Head/neck movement } \\
\text { Attention, agitation, \& impulse control } \\
\text { Executive reasoning }\end{array}$ & $\begin{array}{r}45.2 \\
4.3 \\
26.0 \\
26.0 \\
37.0 \\
37.0 \\
23.0 \\
55.0\end{array}$ & $\begin{array}{r}45.2 \\
4.3 \\
26.0 \\
26.0 \\
50.0 \\
50.0 \\
60.0 \\
55.0\end{array}$ \\
\hline SCI ( $\geq$ C4) & 46,000 & 66,240 & - & 100.0 & $\begin{array}{l}\text { Spasticity } \\
\text { Head/neck movement }\end{array}$ & $\begin{array}{r}12.0 \\
100.0\end{array}$ & $\begin{array}{r}37.0 \\
100.0\end{array}$ \\
\hline
\end{tabular}


not everyone with ALS at any particular time needs a wheelchair or has difficulty operating a wheelchair. In a survey of 42 individuals with ALS who used wheelchairs, respondents reported an average time of 2.1 years from symptom onset to wheelchair purchase [16]. In the same survey, 26 individuals (62\%) indicated that they no longer could use a manual wheelchair independently. However, only 13 of these individuals were using a powered wheelchair [16]. The number of individuals with ALS who use wheelchairs is estimated based on the observation that the average time from symptom onset to wheelchair purchase was 2.1 years [16] and the survival rate at 2 years from symptom onset is 80 percent [17]. This finding leads to an estimate that 80 percent of individuals diagnosed with ALS need a wheelchair for mobility at any given time.

\section{Cerebral Palsy}

Cerebral palsy (CP) results from brain injury occurring before cerebral development is complete. Since the brain continues to develop through the second year of life, CP can be caused from an injury occurring either before or after birth [18]. CP can result in global mental and physical dysfunction or isolated disturbances in gait, cognition, growth, or sensation [18]. In a recent survey of 553 children aged 1 to 12 diagnosed with CP in Canada [19], 78 percent of all respondents had the spastic type of CP, 10 percent had the athetoid type, 2 percent had the ataxic type, and the remaining 10 percent had a mixed type [19]. Overall, 41 percent of the participants were tetraplegic, 10 percent were triplegic, and 15 percent were hemiplegic [19].

Over 750,000 people in the United States have been diagnosed with CP, and 8,000 babies and infants and an additional 1,200 to 1,500 children are diagnosed with CP each year in the United States [20]. Of individuals with $\mathrm{CP}, 86$ percent use a wheelchair at least some of the time but only 5 to 13 percent use powered wheelchairs. The remaining individuals use manual wheelchairs, but only 3 to 9 percent propel their own chair; the others depend on caregivers [19,21].

\section{Cerebrovascular Accident}

A cerebrovascular accident (CVA), or stroke, is a disruption in the brain's blood supply due to arterial occlusion or rupture, causing irreversible neurological impairment [22]. A CVA can result in a wide array of physical, cognitive, or perceptual impairments, depending on which brain hemisphere, or region within the hemisphere, is affected. In addition, many individuals who have had a CVA are older and have additional impairments [23]. Symptoms that can interfere with an individual's ability to operate a wheelchair include visual field neglect, visual field loss, spasticity, and hemiplegia [23-27].

The estimated number of noninstitutionalized CVA survivors is 2.4 million. Each year, approximately 500,000 new CVAs and 200,000 repeat CVAs occur [28]. In a retrospective study that examined the charts of 819 consecutive CVA patients admitted for rehabilitation from 1997 to 2001, 26 percent were using a wheelchair for ambulation when discharged [29]. In a prospective study of 390 patients admitted to a rehabilitation CVA unit, 135 could walk on admission, an additional 196 were walking at discharge, and 59 (15\%) needed a wheelchair for mobility at discharge [30].

\section{Multiple Sclerosis}

Multiple sclerosis (MS) damages the myelin sheath surrounding nerve fibers in the central nervous system (CNS). Symptoms can vary between individuals and within individuals over days or even hours [31]. Demyelination can occur throughout the CNS, so which motor control impairments will occur cannot be predicted. Of people with MS, 85 percent reported gait and motor disturbances as their primary complaint [32]. Symptoms that are relevant to wheelchair use include spasticity, tremors, fatigue, ataxia, and impaired executive reasoning [4,25,33-36].

MS is prevalent in about 250,000 to 350,000 patients in the United States [4,34] and 2.5 million people worldwide [4,32]. The incidence of MS is estimated at six cases per 100,000 population. Approximately 45 percent of individuals with MS $(112,000-158,000)$ are over the age of 55 years [4]. Severe disability is noted in 10 percent of people with MS within 5 years, in 25 percent within 10 years, and in 50 percent within 18 years [37].

Half of individuals with MS require the assistance of another person for everyday mobility [31-32]. Of people with MS, 61 percent reported possessing a manual wheelchair and 8 percent reported owning a powered wheelchair [37]. Most likely, individuals with MS are not receiving mobility devices that allow them to function effectively in their environment [32]. Of individuals with MS who use manual wheelchairs, 59 percent stated they did not feel their current wheelchair met their mobility needs [31].

\section{Multiple System Atrophy}

Multiple system atrophy (MSA) includes a group of progressive neurodegenerative disorders that are often mistaken for Parkinson disease (PD). MSA was originally divided into Shy-Drager syndrome, striatonigral 
degeneration, and olivopontocerebellar atrophy, but this distinction is no longer made. Symptoms of MSA that can interfere with independent wheelchair use include nystagmus, restricted down gaze, spasticity, tremors, ataxia, bradykinesia, dystonia, and impaired executive reasoning skills [38-40].

MSA is prevalent in 1.86 to 4.9 cases per 100,000 population, leading to an estimate of 5,543 to 14,602 cases in the United States. The incidence of MSA is 0.6 cases per 100,000 person-years [41]. A study of 230 Japanese individuals diagnosed with MSA found that 60 percent used wheelchairs [42].

\section{Parkinson Disease}

$\mathrm{PD}$ is a progressive neurodegenerative illness that destroys dopaminergic neurons in the nigrostriatal pathway of the brain [43]. Symptoms of PD include motor abnormalities (tremor, rigidity, bradykinesia, and balance problems) and cognitive impairment [43-44]. PD affects as many as 0.5 percent of individuals aged 60 to 69 years and as many as 2.5 percent of individuals older than 80 years [45]. PD is prevalent in 894,000 of the U.S. population and has an incidence of 8,000 to 18,000 new diagnoses each year. Approximately 10 percent of people with PD use a wheelchair [46].

\section{Progressive Supranuclear Palsy}

Progressive supranuclear palsy (PSP) is a parkinsonian disorder that is frequently mistaken for PD. PSP is characterized by neurodegeneration, gliosis, and abnormal accumulation of protein in the CNS [47]. Symptoms of PSP include postural instability, frequent falling, supranuclear gaze palsy, parkinsonism, subcortical dementia, bradykinesia, and axial rigidity [47-48]. Visual impairments associated with PSP include slowness of vertical saccades, apraxia of lid opening/closing, involuntary closure of the eyelid due to spasms of the orbicularis oculi, and decreased blinking frequency [47].

PSP is prevalent in an estimated 1.39 cases per 100,000 population [48], producing an estimated prevalence in the United States of 4,142. The incidence of PSP among individuals aged 50 to 99 is 5.3 per 100,000 [49]. In a longitudinal study following 50 patients diagnosed with PSP either until death (mean duration of surveillance of 53.6 months) or study conclusion (mean duration of surveillance of 46.2 months) [50], 34 (70\%) required a wheelchair for mobility by the end of the observation period [50]. Of the 44 patients in the study who developed any of the key impairments identified by the investigators,
10 (23\%) reported that a mobility impairment leading to wheelchair use was the first impairment developed [50].

\section{Severe Traumatic Brain Injury}

Several measures are used to describe the severity of a traumatic brain injury (TBI). Two of the more common measures are the Glasgow Coma Scale (GCS) [51] and the Abbreviated Injury Scale (AIS) [52]. A GCS score less than 9 or an AIS score of 5 indicates a severe TBI. Depending on which part of the brain is injured, severe TBI can result in diverse physical, cognitive, and perceptual symptoms. Potential symptoms include visual field neglect, hemiplegia, tremors, bradykinesia, fatigue, and posttraumatic epileptic seizures, in addition to impairments in attention, impulse control, and executive reasoning [53-58].

The number of individuals who are living with a disability from a TBI is estimated to be 5,300,000, with an annual incidence of TBI of 1,500,000 [59]. Approximately 10 percent of people discharged from a hospital with TBI have a severe TBI [60-62]. This finding leads to an estimated prevalence of severe TBI in 530,000 people in the United States. In a retrospective study of individuals admitted to a teaching hospital in Australia 5 years previously, 9 percent of participants relied on a wheelchair for mobility [54].

\section{Spinal Cord Injury At or Above Fourth Cervical Vertebra}

Individuals with a spinal cord injury (SCI) at or above the fourth cervical vertebra (C4) are unable to operate a manual wheelchair. They can also have difficulty operating a powered wheelchair because of spasticity or because their lack of neck movement makes seeing obstacles behind or beside their wheelchair impossible. SCI at any level has been estimated to be prevalent in 200,000 to 288,000 people living in the United States with an SCI [63]. The incidence of SCI has been estimated at 27.1 to 83.0 per million persons a year [63]. Clinical records from 25,000 people who sustained SCI and whose records are now in the national SCI database were evaluated, and 23 percent were found to be classified as complete tetraplegia at discharge [64]. A retrospective study of 161 SCI cases admitted to the University of Louisville Hospital from May 1993 to December 1998 reported 20 percent of patients sustained injuries at or above the C4 level [65]. Applying an estimate of 23 percent to the estimated overall prevalence of 200,000 to 288,000 produces an estimated prevalence of 46,000 to 66,240 people with an SCI at or above the $\mathrm{C} 4$ level. 


\section{Impairments that Affect Wheeled Mobility}

This section discusses the various types of impairments that can interfere with an individual's ability to safely and independently operate a manual or powered wheelchair. Estimates are provided for the number of people who have each type of impairment and use a wheelchair, regardless of disability. These estimates are derived from estimates of (1) the prevalence of a diagnosis, (2) wheelchair use of individuals with the diagnosis, and (3) prevalence of symptoms within the diagnosis. The results of this analysis are summarized in Table 2 .

\section{Upper-Body Physical Impairment}

Physical impairments that reduce the strength or coordination of an individual's arms are often the factors in determining whether an individual needs a manual or a powered wheelchair. Upper-body physical impairments can also interfere with operation of a powered wheelchair. Depending on the specific symptoms, physical impairments can lead to difficulty in reacting to moving or suddenly appearing obstacles, driving long distances, or completing tasks that emphasize hand-eye coordination.

Ataxia. Ataxia is a lack of muscular coordination. A person with ataxia can have difficulties performing wheelchair navigation tasks that require fine motor control or fast reactions. Diagnoses that can produce ataxia include MS (23\%-84\% of cases) [4] and CP (5\%-10\%) [19].

Bradykinesia. Bradykinesia refers to a reduced speed or amplitude of movement. Bradykinesia can interfere with one's ability to react to dynamic obstacles. Diagnoses that can produce bradykinesia include MSA (71\% of cases) [66], PSP (22\%) [48], severe TBI (26\%) [54], and PD (12.5\%) [67].

Dystonia. Dystonia refers to a disorder characterized by abnormal movements or postures resulting from involuntary muscle contractions. Dystonia can interfere with wheelchair navigation tasks requiring fine motor control. Diagnoses that can produce dystonia include MSA (43\% of cases) [66] and CP (17.6\%) [68].

Fatigue or Weakness. Muscle fatigue or weakness can lead to collisions if a wheelchair user cannot quickly respond to a moving or suddenly appearing obstacle. Fatigue or weakness can also make navigating long distances difficult for a wheelchair user. Diagnoses that can produce muscle fatigue or weakness include MS (43\%$90 \%$ of cases) $[4,36]$, severe TBI $(37 \%-50 \%)$ [54,57], and ALS (26\%) [16].
Spasticity. Spasticity refers to a condition in which muscles are continuously contracted, which results in stiffness that interferes with movement. Spasticity in the muscles of the trunk, arms, neck, or head can interfere with one's ability to operate a wheelchair. Diagnoses that can produce spasticity include CVA (35\%-51\% of cases) [23,25], CP (70\%-90\%) [69-70], MSA (10\%) [40], MS (65\%-90\%) [25,34], and SCI (12\%-37\%) [71].

Tremor. Tremor refers to a rhythmic contraction of one or more muscles. Some tremor is only observed when the affected limb is at rest (resting tremor), while other tremor is only observed when the affected limb is performing a fine motor task (intention tremor). Resting tremor is unlikely to interfere with the use of a wheelchair. For example, tremor is also present in 70 to 80 percent of individuals with PD [45], but this is typically a resting tremor and is therefore unlikely to affect their ability to operate a wheelchair. Persistent tremor, or intention tremor, on the other hand, can interfere with navigation tasks requiring fine motor control or may cause unintended collisions with objects. Diagnoses that can produce tremor include MS (75\% of cases) [72-73], CP (10\%-20\%) [19], MSA (67\%) [40], PSP (12\%-16\%) [48], and severe TBI (26\%) [54].

\section{Cognitive Impairment}

Operating a wheelchair, whether manual or powered, is a complex task requiring skills in navigation, planning, and problem solving [74]. Wheelchairs are also potentially dangerous to the user and other people in the environment and, therefore, require control of one's impulses and emotions. Impairments in cognitive function can lead to difficulty constructing or remembering a path to a destination, difficulty concentrating on wheelchair navigation or dividing attention between wheelchair navigation and a second task, or intentionally colliding with obstacles or people [74].

Impaired Attention, Agitation, or Impulse Control. Neurological impairments can cause difficulties with concentration, attention, and mood control. Without these skills, a wheelchair user can easily become confused, distracted, or agitated, leading to aggression and violence. Diagnoses that can lead to these impairments include AD (48\%) [75] and severe TBI (23\%-60\%) [54,56-57,76].

Deficits in Executive Reasoning. The term executive reasoning captures a constellation of cognitive skills necessary for goal-directed behavior, including judgment, reasoning, planning, problem solving, decision making, and 
JRRD, Volume 45, Number 1, 2008

Table 2.

Potential smart wheelchairs users, organized by symptom.

\begin{tabular}{|c|c|c|c|c|c|c|c|}
\hline \multirow[b]{2}{*}{ Symptom } & \multirow[b]{2}{*}{ Diagnosis } & \multicolumn{2}{|c|}{ Prevalence } & \multicolumn{2}{|c|}{ \% Need Wheelchair } & \multicolumn{2}{|c|}{ \% with Symptom } \\
\hline & & $\begin{array}{c}\text { Lowest } \\
\text { Estimate }\end{array}$ & $\begin{array}{l}\text { Highest } \\
\text { Estimate }\end{array}$ & $\begin{array}{c}\text { Lowest } \\
\text { Estimate }\end{array}$ & $\begin{array}{l}\text { Highest } \\
\text { Estimate }\end{array}$ & $\begin{array}{c}\text { Lowest } \\
\text { Estimate }\end{array}$ & $\begin{array}{c}\text { Highest } \\
\text { Estimate }\end{array}$ \\
\hline \multirow{2}{*}{$\overline{\text { Ataxia }}$} & $\mathrm{CP}$ & 750,000 & 750,000 & - & 86.0 & 5.0 & 10.0 \\
\hline & MSA & 5,543 & 14,602 & - & 60.0 & 56.0 & 86.8 \\
\hline \multirow[t]{2}{*}{ Bradykinesia } & MSA & 5,543 & 14,602 & - & 60.0 & 71.0 & 97.6 \\
\hline & PD & 894,000 & 894,000 & - & 10.0 & - & 12.5 \\
\hline \multirow[t]{2}{*}{ Dystonia } & $\mathrm{CP}$ & 750,000 & 750,000 & - & 86.0 & - & 17.6 \\
\hline & MSA & 5,543 & 14,602 & - & 60.0 & 31.0 & 43.0 \\
\hline \multirow[t]{3}{*}{ Fatigue/Weakness } & ALS & 25,000 & 30,000 & 46.0 & 80.0 & - & 26.0 \\
\hline & Severe TBI & 530,000 & 530,000 & - & 9.0 & 37.0 & 50.0 \\
\hline & MS & 250,000 & 350,000 & - & 69.0 & 43.0 & 90.0 \\
\hline & MS & 250,000 & 350,000 & - & 69.0 & 65.0 & 90.0 \\
\hline & MSA & 5,543 & 14,602 & - & 60.0 & - & 10.0 \\
\hline \multirow[t]{6}{*}{ Tremor } & $\mathrm{CP}$ & 750,000 & 750,000 & - & 86.0 & 10.0 & 20.0 \\
\hline & MS & 250,000 & 350,000 & - & 69.0 & - & 6.0 \\
\hline & MSA & 5,543 & 14,602 & - & 60.0 & 52.0 & 84.3 \\
\hline & PD & 894,000 & 894,000 & - & 10.0 & - & 63.0 \\
\hline & Severe TBI & 530,000 & 530,000 & - & 9.0 & - & 26.0 \\
\hline & PSP & 4,142 & 4,142 & - & 70.0 & 5.0 & 21.0 \\
\hline \multirow[t]{2}{*}{ Attention, Agitation, \& Impulse Control } & $\mathrm{AD}$ & $2,300,000$ & $4,000,000$ & - & 15.0 & - & 48.0 \\
\hline & Severe TBI & 530,000 & 530,000 & - & 9.0 & 23.0 & 60.0 \\
\hline Blindness & Legally blind & $1,057,389$ & $1,057,389$ & - & 9.6 & - & 100.0 \\
\hline \multirow[t]{4}{*}{ Head/Neck Movement } & $\mathrm{SCI}(\geq \mathrm{C} 4)$ & 46,000 & 66,240 & - & 100.0 & - & 100.0 \\
\hline & ALS & 25,000 & 30,000 & 46.0 & 80.0 & - & 26.0 \\
\hline & Severe TBI & 530,000 & 530,000 & - & 9.0 & 37.0 & 50.0 \\
\hline & MS & 250,000 & 350,000 & - & 69.0 & 43.0 & 90.0 \\
\hline \multirow[t]{2}{*}{ Impaired Eye Movement } & PSP & 4,142 & 4,142 & - & 70.0 & - & 6.0 \\
\hline & MSA & 5,543 & 14,602 & - & 60.0 & 10.0 & 37.0 \\
\hline \multirow[t]{2}{*}{ Visual Field Loss } & CVA (right-hemisphere) & $1,200,000$ & $1,200,000$ & 15.0 & 25.0 & - & 20.0 \\
\hline & CVA (left-hemisphere) & $1,200,000$ & $1,200,000$ & 15.0 & 25.0 & - & 20.0 \\
\hline \multirow[t]{4}{*}{ Visual Field Neglect } & CVA (right-hemisphere) & $1,200,000$ & $1,200,000$ & 15.0 & 25.0 & 13.0 & 82.0 \\
\hline & CVA (left-hemisphere) & $1,200,000$ & $1,200,000$ & 15.0 & 25.0 & 0.0 & 76.0 \\
\hline & Severe TBI & 530,000 & 530,000 & - & 9.0 & - & 45.2 \\
\hline & $\mathrm{PD}$ & 894,000 & 894,000 & - & 10.0 & - & 90.0 \\
\hline
\end{tabular}


sequencing actions [77-79]. Impaired executive reasoning skills can dramatically reduce one's ability to successfully operate a wheelchair. Diagnoses that can produce deficits in executive reasoning include CP (64\% of cases) [80], PSP (50\%) [48], MSA (0.5\%-17.0\%) [39-40], MS (30\%$70 \%)$ [33], severe TBI (55\%) [55], and AD (41\%) [81].

\section{Visual Impairment and Wheeled Mobility}

A visual impairment can affect a person's ability to operate a manual or powered wheelchair in several ways. Regardless of the underlying clinical diagnosis, visual impairment can make seeing obstacles or navigational cues difficult. A visual impairment can also increase the difficulty of navigation tasks that emphasize hand-eye coordination, such as passing through a narrow doorway or docking at a table.

Low Vision or Blindness. The term low vision refers to individuals who have impaired vision, but their vision is correctable to the point where they do not meet the criteria for legal blindness. An individual is legally blind if his or her visual acuity is no better than $20 / 200$, even with corrective lenses. Operating a wheelchair with little or no functional vision is obviously difficult. Some individuals can operate a wheelchair with assistance of a cane or guide dog [82-84], but this assistance is rarely observed in practice.

Head/Neck Movement. An individual can have impaired vision without having any impairment to the visual system. Individuals who use a wheelchair and have difficulty moving their head risk colliding with obstacles they cannot see. Limited head/neck movement is particularly important when wheelchair users back up, since they have difficulty seeing obstacles behind the wheelchair. Diagnoses that can result in limited head/neck movement include SCI above the C4 level $(100 \%$ of cases), ALS (26\%) [16], and MS (43\%-90\%) [4,36].

Eye Movement Impairment. Impairments of eye movement include nystagmus, restricted eye movement, difficulty initiating saccades, and poor saccadic pursuit. Impaired eye movement can interfere with a wheelchair user's ability to detect obstacles or see navigational cues. Diagnoses that can produce impairments in eye movement include MSA (restricted down gaze in $10 \%$ of cases, nystagmus in 23\% of cases) [40] and PSP (6\%) [85].

Visual Field Loss. Visual field loss results in a restricted or "spotty" view of the world. For wheelchair users, visual field loss increases the risk of colliding with obstacles or missing important navigational cues that fall outside the remaining visual field. Among other diagnoses, visual field neglect can result from right- or lefthemisphere CVA (20\% of cases) [24].

Visual Field Neglect. Visual field neglect (also referred to as hemineglect or unilateral neglect) is a condition in which an individual behaves as if the neglected half of the world does not exist [86-87]. Individuals with visual field neglect have slower reaction times to stimuli in the neglected space and are less likely to scan the neglected space for obstacles [86-87]. For wheelchair users, visual field neglect increases the risk of colliding with obstacles or missing important navigational cues in the neglected side. Among other diagnoses, visual field neglect can result from right-hemisphere CVA (13\%$82 \%$ of cases), left-hemisphere CVA (0\%-76\%) [24], or severe TBI (45\%) [58].

\section{DISCUSSION}

\section{What Navigation Capabilities Are Needed?}

A wide range of capabilities has been envisioned for smart wheelchairs [8]. For this discussion, these capabilities are roughly divided into autonomous navigation and obstacle avoidance.

\section{How Many Wheelchair Users Might Benefit from Autonomous Navigation?}

A smart wheelchair that provides autonomous navigation can perform an entire navigation task, or an entire component of a navigation task, without intervention from the user. The smart wheelchair may be planning a route based on an internal map of its environment, reproducing a preprogrammed path, or completing a specific component of a navigation task (e.g., backing out of a bathroom, passing through a narrow doorway), but the common factor is limited effort of the user in exchange for limited control over that actual path of travel. This type of assistance would be useful for wheelchair users-

- With cognitive impairments who cannot remember where they are going, cannot remember how to get there, or have trouble with problem solving.

- Who fatigue easily, making navigating over long distances difficult.

- With visual impairments that make identifying navigation cues in the environment difficult or impossible.

Relevant symptoms include blindness, low vision, visual field loss, visual field neglect, impaired eye 
movement, fatigue, and executive reasoning dysfunction. Diagnoses that can produce these symptoms include AD, ALS, CP, CVA, blindness, low vision, MS, MSA, PD, PSP, and severe TBI. The estimated number of individuals who (1) have one of these diagnoses, (2) have at least one of these symptoms, and (3) need a wheelchair is shown in Table 3. If it is assumed that, within a diagnosis, any individual with the most common symptom also has every one of the less common symptoms, then the number of individuals who need a smart wheelchair that provides autonomous navigation is 973,706 to $1,700,107$.

\section{How Many Wheelchair Users Might Benefit from Obstacle Avoidance?}

A smart wheelchair that provides obstacle avoidance but does not provide any path-planning assistance gives greater control to the user, at the cost of increased user effort. Smart wheelchairs in this category would potentially be useful for wheelchair users with-

- Visual impairments who might not see obstacles but are able to navigate without visual cues.

- Physical impairments that can cause them temporarily to lose control of the chair.

- Cognitive impairments that make driving unsafe (e.g., poor impulse control).

Relevant symptoms include spasticity, tremor, dystonia, bradykinesia, blindness, low vision, visual field neglect, and impaired attention or impulse control. Diagnoses that can produce these symptoms include AD, ALS, CP, CVA, blindness or low vision, MS, MSA, PD, PSP, severe TBI, or SCI at or above C4. The estimated number of individuals who (1) have one of these diagnoses, (2) have at least one of these symptoms, and (3) need a

Table 3.

Potential users of smart wheelchairs that provide autonomous navigation, organized by diagnosis.

\begin{tabular}{|c|c|c|c|c|c|c|c|c|c|}
\hline Diagnosis & \multicolumn{2}{|c|}{ Prevalence } & \multicolumn{2}{|c|}{ \% Need Wheelchair } & Symptom & \multicolumn{2}{|c|}{ \% with Symptom } & \multicolumn{2}{|c|}{$\begin{array}{l}\text { No. Need Smart } \\
\text { Wheelchair }\end{array}$} \\
\hline$\overline{\mathrm{AD}}$ & $2,300,000$ & $4,000,000$ & 15.0 & 15.0 & Executive reasoning & 41.0 & 41.0 & 141,450 & 246,000 \\
\hline ALS & 25,000 & 30,000 & 46.0 & 80.0 & Fatigue/weakness & 26.0 & 26.0 & 2,990 & 6,240 \\
\hline $\mathrm{CP}$ & 750,000 & 750,000 & 86.0 & 86.0 & Executive reasoning & 30.0 & 41.0 & 193,500 & 264,450 \\
\hline CVA (right-hemisphere) & $1,200,000$ & $1,200,000$ & 15.0 & 25.0 & Visual field neglect & 13.0 & 82.0 & 23,400 & 246,000 \\
\hline \multirow[t]{2}{*}{ CVA (left-hemisphere) } & $1,200,000$ & $1,200,000$ & 15.0 & 25.0 & Visual field neglect & 0.0 & 76.0 & 0 & 228,000 \\
\hline & & & & & Visual field loss & 20.0 & 20.0 & 36,000 & 60,000 \\
\hline Legally Blind & $1,057,389$ & $1,057,389$ & 9.6 & 9.6 & Blindness & 100.0 & 100.0 & 101,615 & 101,615 \\
\hline Low Vision & $5,315,541$ & $5,315,541$ & 5.3 & 5.3 & Low vision & 100.0 & 100.0 & 279,066 & 279,066 \\
\hline MS & 250,000 & 350,000 & 69.0 & 69.0 & Fatigue/weakness & 43.0 & 90.0 & 74,175 & 217,350 \\
\hline MSA & & & & & Executive reasoning & 0.5 & 17.0 & 17 & 1,489 \\
\hline \multirow[t]{2}{*}{$\mathrm{PD}$} & 894,000 & 894,000 & 10.0 & 10.0 & Visual field neglect & 90.0 & 90.0 & 80,460 & 80,460 \\
\hline & & & & & Executive reasoning & 23.0 & 44.0 & 20,562 & 39,336 \\
\hline \multirow[t]{2}{*}{ PSP } & 4,142 & 4,142 & 70.0 & 70.0 & Impaired eye movement & 6.0 & 6.0 & 174 & 174 \\
\hline & & & & & Executive reasoning & 50.0 & 50.0 & 1,450 & 1,450 \\
\hline \multirow[t]{3}{*}{ Severe TBI (AIS 5 or GCS < 9) } & 530,000 & 530,000 & 9.0 & 9.0 & Visual field neglect & 45.2 & 45.2 & 21,560 & 21,560 \\
\hline & & & & & Fatigue/weakness & 37.0 & 50.0 & 17,649 & 23,850 \\
\hline & & & & & Executive reasoning & 55.0 & 55.0 & 26,235 & 26,235 \\
\hline Total $^{*}$ & - & - & - & - & - & - & - & 973,706 & $1,700,107$ \\
\hline $\begin{array}{l}{ }^{*} \text { Conservative estimates for nu } \\
\text { sumes the set of people with an } \\
\mathrm{AD}=\text { Alzheimer disease, AIS } \\
\text { gow Coma Scale, MS = multi } \\
\text { injury, TBI = traumatic brain ir }\end{array}$ & of pot & $\begin{array}{l}\text { sers. } \\
\text { Hence }\end{array}$ & 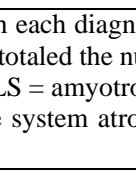 & 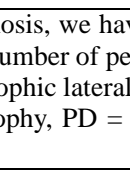 & 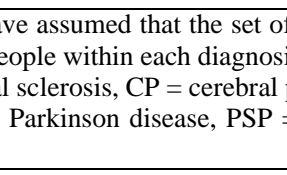 & 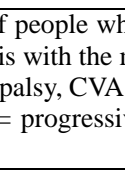 & have & prevalent & $\begin{array}{l}\text { nptom sub } \\
\text { ptom. } \\
\text { CS = Glas }\end{array}$ \\
\hline
\end{tabular}


wheelchair is shown in Table 4. If one assumes that, within a diagnosis, any individual with the most common symptom also has every one of the less common symptoms, then the number of individuals who need a smart wheelchair that provides obstacle avoidance is $1,389,916$ to $2,133,280$.

\section{What Form Factor Is Needed?}

Smart wheelchairs are typically based on powered wheelchairs, but the advent of power-assist wheelchair hubs [88] has created the possibility of a smart wheelchair based on a manual wheelchair frame [89].

Table 4.

Potential users of smart wheelchairs that provide obstacle avoidance, organized by diagnosis.

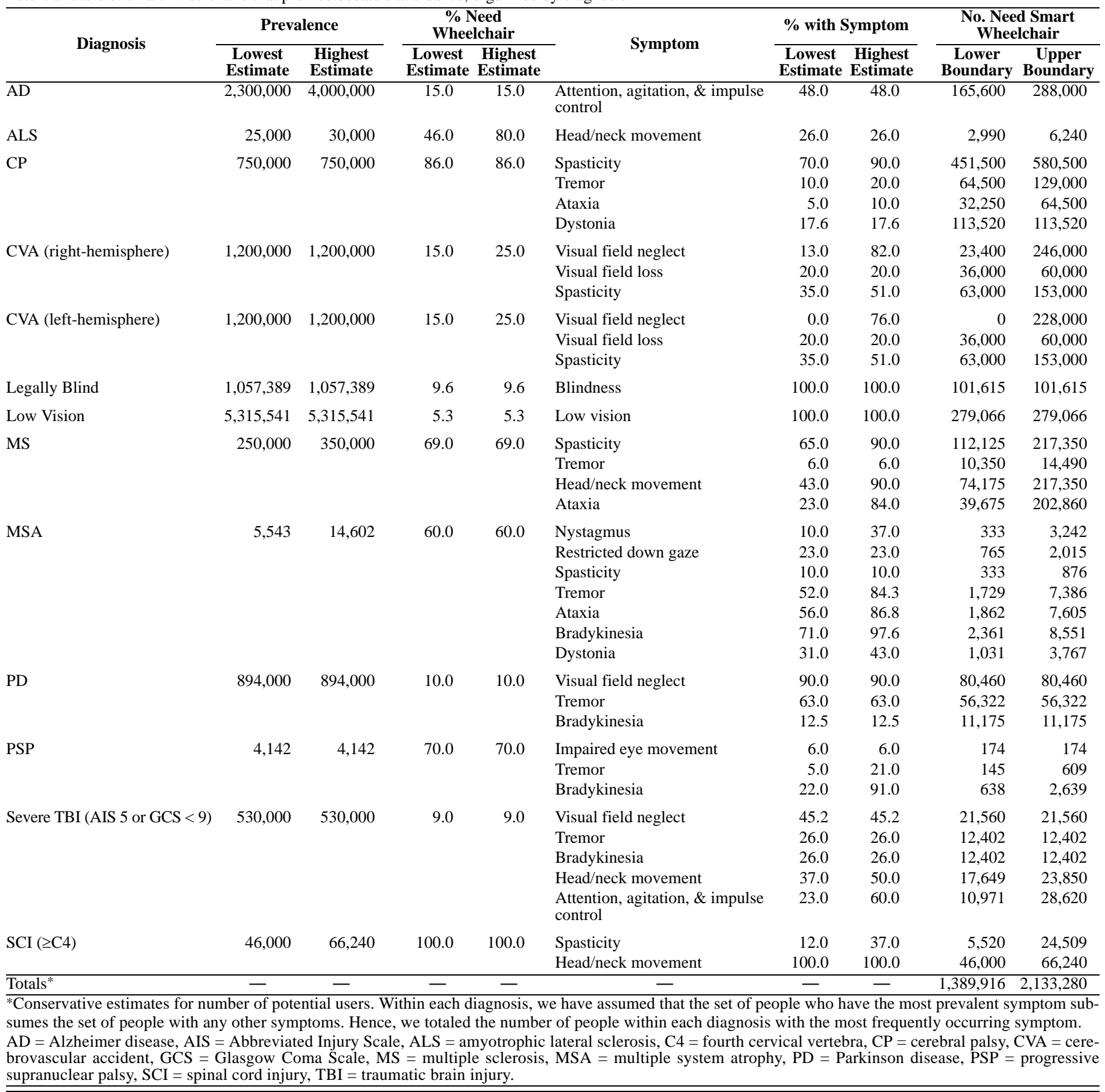


How Many Wheelchair Users Might Benefit from a Smart Manual Wheelchair?

Manual wheelchairs are preferred over powered wheelchairs for various reasons. In general, manual wheelchairs are lighter and more maneuverable than powered wheelchairs and can be transported in a car. Manual wheelchairs that use power-assist hubs are heavier than traditional manual wheelchairs. They can be more difficult to disassemble for transport depending on how the hubs are attached to the frames but still provide many of the advantages of traditional manual wheelchairs. A smart manual wheelchair would be useful for wheelchair users with hemiplegia and wheelchair users with visual impairments who have good motor control in at least one arm.

Hemiplegia, by itself, does not interfere with one's ability to operate a powered wheelchair, but it does make operating a manual wheelchair much more difficult. The current solutions for manual wheelchair users with hemiplegia are "one-arm drive" mechanisms or foot-driven wheelchairs [90]. A smart manual wheelchair could provide smooth travel by compensating for uneven propulsion forces on the right and left wheels and augmenting total propulsion force, while preserving the user's safety through obstacle avoidance.

Diagnoses that can result in hemiplegia include CVA (50\% of cases) [28], severe TBI (4\%) [53], and CP
(15\%) [19]. Diagnoses of combined visual and mobility impairment include CVA, blindness and low vision, PD, and severe TBI. The estimated number of individuals who (1) have one of these diagnoses, (2) have at least one of these symptoms, and (3) need a wheelchair is shown in Table 5. If it is assumed that, within a diagnosis, any individual with the most common symptom also has every one of the less common symptoms, then the number of individuals who need a smart manual wheelchair is 759,346 to $1,053,451$.

\section{How Many Wheelchair Users Might Benefit from a Smart Powered Wheelchair?}

A wheelchair user who needs a smart wheelchair might not be able to use a manual wheelchair but would be expected to be able to use a powered wheelchair. Hence, as shown in Table 6, any smart wheelchair user might benefit from a smart powered wheelchair. Individuals with hemiplegia have been excluded from this count because they are considered most likely to be able to use (and prefer) a smart manual wheelchair. If any individual with the most common symptom is assumed also to have every one of the less common symptoms within a diagnosis, then the number of individuals who need a smart powered wheelchair is 1,395,402 to $2,133,280$.

Table 5.

Potential smart manual wheelchair users, organized by diagnosis.

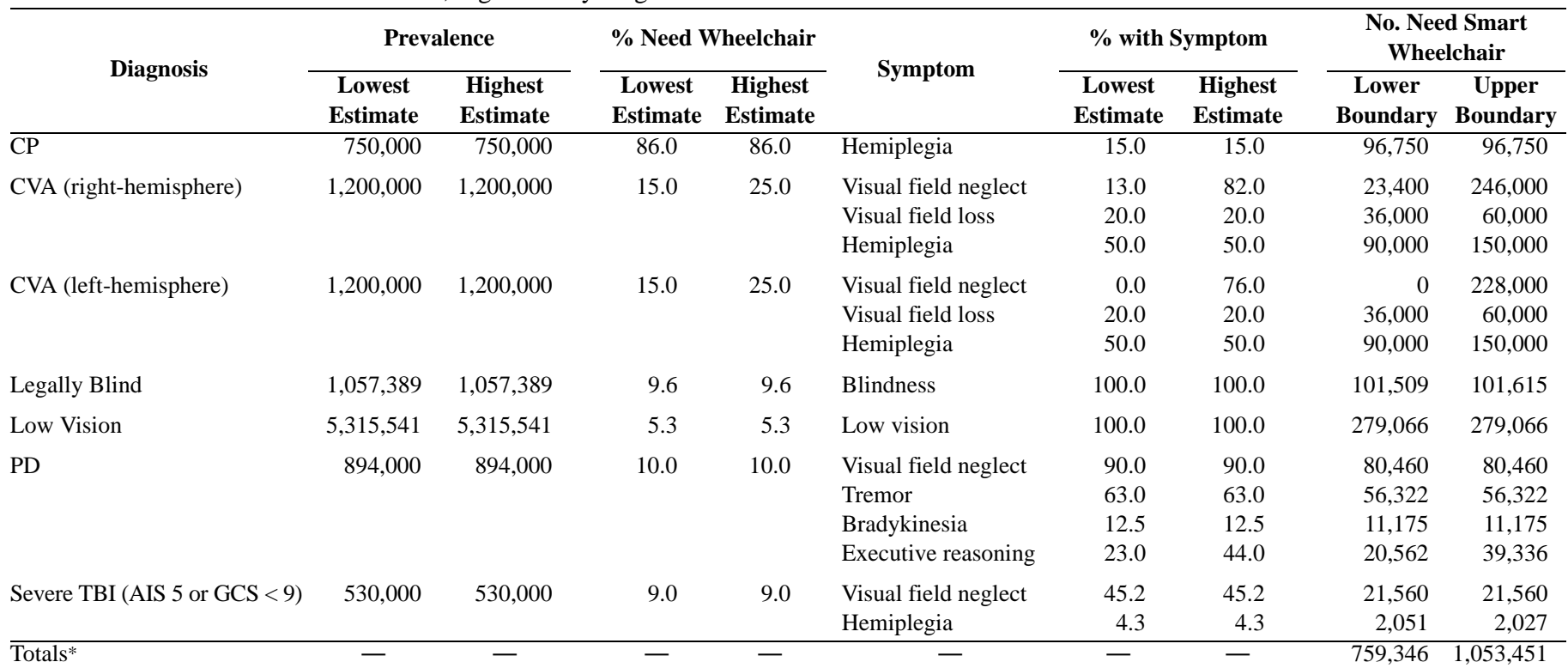

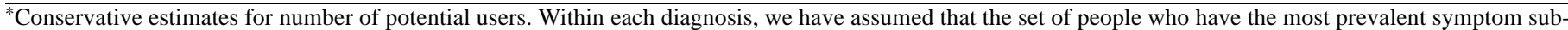
sumes the set of people with any other symptoms. Hence, we totaled the number of people within each diagnosis with the most frequently occurring symptom.

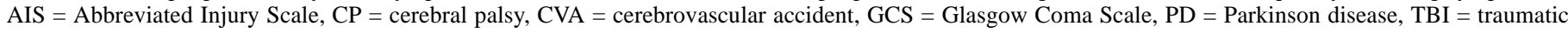
brain injury. 
Table 6.

Potential smart powered wheelchair users, organized by diagnosis.

\begin{tabular}{|c|c|c|c|c|c|c|c|c|c|}
\hline \multirow{2}{*}{ Diagnosis } & \multicolumn{2}{|c|}{ Prevalence } & \multicolumn{2}{|c|}{$\begin{array}{c}\text { \% Need } \\
\text { Wheelchair }\end{array}$} & \multirow{2}{*}{ Symptoms } & \multicolumn{2}{|c|}{ \% with Symptom } & \multicolumn{2}{|c|}{$\begin{array}{l}\text { No. Need Smart } \\
\text { Wheelchair }\end{array}$} \\
\hline & $\begin{array}{c}\text { Lowest } \\
\text { Estimate }\end{array}$ & $\begin{array}{l}\text { Highest } \\
\text { Estimate }\end{array}$ & $\begin{array}{l}\text { Lowest } \\
\text { Estimate }\end{array}$ & $\begin{array}{l}\text { Highest } \\
\text { Estimate }\end{array}$ & & $\begin{array}{c}\text { Lowest } \\
\text { Estimate }\end{array}$ & $\begin{array}{l}\text { Highest } \\
\text { Estimate }\end{array}$ & $\begin{array}{c}\text { Lower } \\
\text { Boundary }\end{array}$ & $\begin{array}{c}\text { Upper } \\
\text { Boundary }\end{array}$ \\
\hline$\overline{\mathrm{AD}}$ & $2,300,000$ & $4,000,000$ & 15.0 & 15.0 & $\begin{array}{l}\text { Attention, agitation, \& impulse control } \\
\text { Executive reasoning }\end{array}$ & $\begin{array}{l}48.0 \\
41.0\end{array}$ & $\begin{array}{l}48.0 \\
41.0\end{array}$ & $\begin{array}{l}165,600 \\
141,450\end{array}$ & $\begin{array}{l}288,000 \\
246,000\end{array}$ \\
\hline ALS & 25,000 & 30,000 & 46.0 & 80.0 & $\begin{array}{l}\text { Fatigue/weakness } \\
\text { Head/neck movement }\end{array}$ & $\begin{array}{l}26.0 \\
26.0\end{array}$ & $\begin{array}{l}26.0 \\
26.0\end{array}$ & $\begin{array}{l}2,990 \\
2,990\end{array}$ & $\begin{array}{l}6,240 \\
6,240\end{array}$ \\
\hline $\mathrm{CP}$ & 750,000 & 750,000 & 86.0 & 86.0 & $\begin{array}{l}\text { Spasticity } \\
\text { Tremor } \\
\text { Ataxia } \\
\text { Dystonia } \\
\text { Executive reasoning } \\
\text { Spasticity }\end{array}$ & $\begin{array}{r}70.0 \\
10.0 \\
5.0 \\
17.6 \\
30.0 \\
70.0\end{array}$ & $\begin{array}{l}90.0 \\
20.0 \\
10.0 \\
17.6 \\
41.0 \\
90.0\end{array}$ & $\begin{array}{r}451,500 \\
64,500 \\
32,250 \\
113,520 \\
193,500 \\
451,500\end{array}$ & $\begin{array}{r}580,500 \\
129,000 \\
64,500 \\
113,520 \\
264,450 \\
580,500\end{array}$ \\
\hline CVA (right-hemisphere) & $1,200,000$ & $1,200,000$ & 15.0 & 25.0 & $\begin{array}{l}\text { Visual field neglect } \\
\text { Visual field loss } \\
\text { Spasticity }\end{array}$ & $\begin{array}{l}13.0 \\
20.0 \\
35.0\end{array}$ & $\begin{array}{l}82.0 \\
20.0 \\
51.0\end{array}$ & $\begin{array}{l}23,400 \\
36,000 \\
63,000\end{array}$ & $\begin{array}{r}246,000 \\
60,000 \\
153,000\end{array}$ \\
\hline CVA (left-hemisphere) & $1,200,000$ & $1,200,000$ & 15.0 & 25.0 & $\begin{array}{l}\text { Visual field neglect } \\
\text { Visual field loss } \\
\text { Spasticity }\end{array}$ & $\begin{array}{r}0.0 \\
20.0 \\
35.0\end{array}$ & $\begin{array}{l}76.0 \\
20.0 \\
51.0\end{array}$ & $\begin{array}{r}0 \\
36,000 \\
63,000\end{array}$ & $\begin{array}{r}228,000 \\
60,000 \\
153,000\end{array}$ \\
\hline Legally Blind & $1,057,389$ & $1,057,389$ & 9.6 & 9.6 & Blindness & 100.0 & 100.0 & 101,615 & 101,615 \\
\hline Low Vision & $5,315,541$ & $5,315,541$ & 5.3 & 5.3 & Low vision & 100.0 & 100.0 & 279,066 & 279,066 \\
\hline MS & 250,000 & 350,000 & 69.0 & 69.0 & $\begin{array}{l}\text { Spasticity } \\
\text { Tremor } \\
\text { Fatigue/weakness } \\
\text { Head/neck movement } \\
\text { Ataxia } \\
\text { Executive Reasoning }\end{array}$ & $\begin{array}{r}65.0 \\
6.0 \\
43.0 \\
43.0 \\
23.0 \\
30.0\end{array}$ & $\begin{array}{r}90.0 \\
6.0 \\
90.0 \\
90.0 \\
84.0 \\
70.0\end{array}$ & $\begin{array}{r}112,125 \\
10,350 \\
74,175 \\
74,175 \\
39,675 \\
51,750\end{array}$ & $\begin{array}{r}217,350 \\
14,490 \\
217,350 \\
217,350 \\
202,860 \\
169,050\end{array}$ \\
\hline MSA & 5,543 & 14,602 & 60.0 & 60.0 & $\begin{array}{l}\text { Nystagmus } \\
\text { Restricted down gaze } \\
\text { Spasticity } \\
\text { Tremor } \\
\text { Ataxia } \\
\text { Bradykinesia } \\
\text { Dystonia } \\
\text { Executive reasoning }\end{array}$ & $\begin{array}{r}10.0 \\
23.0 \\
10.0 \\
52.0 \\
56.0 \\
71.0 \\
31.0 \\
0.5\end{array}$ & $\begin{array}{l}37.0 \\
23.0 \\
10.0 \\
84.3 \\
86.8 \\
97.6 \\
43.0 \\
17.0\end{array}$ & $\begin{array}{r}333 \\
765 \\
333 \\
1,729 \\
1,862 \\
2,361 \\
1,031 \\
17\end{array}$ & $\begin{array}{r}3,242 \\
2,015 \\
876 \\
7,386 \\
7,605 \\
8,551 \\
3,767 \\
1,489\end{array}$ \\
\hline PD & 894,000 & 894,000 & 10.0 & 10.0 & $\begin{array}{l}\text { Visual field neglect } \\
\text { Tremor } \\
\text { Bradykinesia } \\
\text { Executive reasoning }\end{array}$ & $\begin{array}{l}90.0 \\
63.0 \\
12.5 \\
23.0\end{array}$ & $\begin{array}{l}90.0 \\
63.0 \\
12.5 \\
44.0\end{array}$ & $\begin{array}{l}80,460 \\
56,322 \\
11,175 \\
20,562\end{array}$ & $\begin{array}{l}80,460 \\
56,322 \\
11,175 \\
39,336\end{array}$ \\
\hline PSP & 4,142 & 4,142 & 70.0 & 70.0 & $\begin{array}{l}\text { Impaired eye movement } \\
\text { Tremor } \\
\text { Bradykinesia } \\
\text { Executive reasoning }\end{array}$ & $\begin{array}{r}6.0 \\
5.0 \\
22.0 \\
50.0\end{array}$ & $\begin{array}{r}6.0 \\
21.0 \\
91.0 \\
50.0\end{array}$ & $\begin{array}{r}174 \\
145 \\
638 \\
1,450\end{array}$ & $\begin{array}{r}174 \\
609 \\
2,639 \\
1,450\end{array}$ \\
\hline Severe TBI (AIS 5 or GCS < 9) & 530,000 & 530,000 & 9.0 & 9.0 & $\begin{array}{l}\text { Visual field neglect } \\
\text { Tremor } \\
\text { Bradykinesia } \\
\text { Fatigue/weakness } \\
\text { Head/neck movement } \\
\text { Attention, agitation, \& impulse control } \\
\text { Executive reasoning }\end{array}$ & $\begin{array}{l}45.2 \\
26.0 \\
26.0 \\
37.0 \\
37.0 \\
23.0 \\
55.0\end{array}$ & $\begin{array}{l}45.2 \\
26.0 \\
26.0 \\
50.0 \\
50.0 \\
60.0 \\
55.0\end{array}$ & $\begin{array}{l}21,560 \\
12,402 \\
12,402 \\
17,649 \\
17,649 \\
10,971 \\
26,235\end{array}$ & $\begin{array}{l}21,560 \\
12,402 \\
12,402 \\
23,850 \\
23,850 \\
28,620 \\
26,235\end{array}$ \\
\hline $\mathrm{SCI}(\geq \mathrm{C} 4)$ & 46,000 & 66,240 & 100.0 & 100.0 & $\begin{array}{l}\text { Spasticity } \\
\text { Head/neck movement }\end{array}$ & $\begin{array}{r}12.0 \\
100.0\end{array}$ & $\begin{array}{r}37.0 \\
100.0\end{array}$ & $\begin{array}{r}5,520 \\
46,000\end{array}$ & $\begin{array}{l}24,509 \\
66,240\end{array}$ \\
\hline $\begin{array}{l}\text { Totals* } \\
\text { *Conservative estimates for nur } \\
\text { sumes the set of people with an } \\
\text { AD = Alzheimer disease, AIS } \\
\text { brovascular accident, GCS = Gl } \\
\text { clear palsy, SCI = spinal cord in }\end{array}$ & $\begin{array}{l}\text { - } \\
\text { er of pot } \\
\text { ther syn } \\
\text { Abbrevia } \\
\text { gow Con } \\
\text { ry, TBI }\end{array}$ & $\begin{array}{l}- \\
\text { ial users. } \\
\text { Ins. Hen } \\
\text { Injury S } \\
\text { Scale, MS }\end{array}$ & $\begin{array}{l}\text { - } \\
\text { in each } \\
\text { e totalec } \\
\text { ALS = }\end{array}$ & $\begin{array}{l}\text { d the numb } \\
\text { amyotropl } \\
\text { sclerosis, I }\end{array}$ & $\begin{array}{l}\text {, we have assumed that the set of peo } \\
\text { ber of people within each diagnosis wi } \\
\text { hic lateral sclerosis, C4 = fourth cervi } \\
\text { MSA = multiple system atrophy, PD = }\end{array}$ & $\begin{array}{l}\frac{-}{\text { pple who l }} \\
\text { ith the mo } \\
\text { ical verte } \\
=\text { Parkinso }\end{array}$ & $\begin{array}{l}- \\
\text { je the } n \\
\text { frequer } \\
\text {, } \mathrm{CP}= \\
\text { disease, }\end{array}$ & $\begin{array}{l}1,395,402 \\
\text { prevalent s } \\
\text { occurring s } \\
\text { ebral palsy, } \\
\text { P = progres }\end{array}$ & $\begin{array}{l}\text { 2,133,280 } \\
\text { mptom sub } \\
\text { mptom. } \\
\text { CVA = cere } \\
\text { ive supranu }\end{array}$ \\
\hline
\end{tabular}




\section{What Other Features Would Be Beneficial?}

Similar analyses may be possible to estimate the number of wheelchair users who might benefit from other features that have been proposed for smart wheelchairs. For example, several investigators have used smart wheelchairs to explore alternative input methods, particularly voice [91-92] and eye gaze [93-94]. Voice control of wheelchairs was being pursued as early as 1985 [95] with limited success. Simpson and Levine demonstrated, however, that combining voice input with the obstacle avoidance capabilities of a smart wheelchair was much more effective than voice input alone [96]. Voice input is potentially useful for controlling a wheelchair directly or for specifying a destination for autonomous navigation. Either application requires sufficient voice clarity and consistency to interact with an automatic speech recognition system. Controlling a wheelchair directly further requires the ability to speak commands rapidly and in sequence to perform some complicated maneuvers.

Another potential application of smart wheelchair technology is facilitating use of cars, vans, and buses. An example of this type of application is the Automated Transport and Retrieval System (ATRS) [97], which combines smart wheelchair technology, an articulating car seat, and a platform lift to allow wheelchair users to independently load and unload their wheelchair from a minivan. The user population for the ATRS consists of wheelchair users who can independently transfer from their wheelchair to a car seat but cannot independently stow or retrieve their wheelchair in a car.

\section{Can International Classification of Functioning, Disability and Health Give Us a More Accurate Estimate?}

The question being addressed seems relatively straightforward: How many people who need to use a wheelchair find it difficult or impossible to do so at least some of the time? Unfortunately, this question is difficult to answer using research that categorizes people based on diagnoses and symptoms (which predominates the literature). The International Classification of Functioning, Disability and Health (ICF) [98], on the other hand, poses the same question with a much simpler method.

The ICF codes the activity of "moving around using equipment” (including wheelchairs) as d465. This code can be further qualified based on whether (1) a person finds the activity difficult (a value of 3 ) or impossible (a value of 4) in their actual environment, (2) the person would find it difficult or impossible in a "standardized" environment without technological or personal assistance, ${ }^{*}$ (3) the person would find it difficult or impossible in a "standardized" environment with technological or personal assistance, and (4) a person finds it difficult (a value of 3) or impossible (a value of 4 ) in the actual environment without technological or personal assistance. The resulting qualified code for a given individual, based on the environment he or she is in at the moment along with his or her physical, perceptual, and cognitive abilities, is 465.abcd, where a, b, c, and d are integers from 0 (no difficulty) to 4 (complete difficulty). As persons move between environments in the wheelchair, or as their physical, perceptual, and cognitive abilities change, the value of "a” would change.

With the use of the ICF coding scheme, the question then becomes, "How many people who use a wheelchair (engage in activity d465) are categorized as having severe difficulty (d465.3bcd) or complete inability (d465.4bcd) at least some of the time?" Note how posing the question this way completely sidesteps the issue of diagnosis and symptoms. Under the ICF coding scheme, the question could also be posed hypothetically as, "How many people who use a wheelchair (engage in activity d465) and who are categorized as having severe difficulty (d465.a3cd) or complete inability (d465.a4cd) in a standardized environment would be able to perform the same activity with little (d465.ab1d) or no (d465.ab0d) difficulty in the same standardized environment when given sufficient assistance?” In this case, a smart wheelchair would be considered one of many interventions that could be applied to the environment to facilitate mobility.

\footnotetext{
* One point that is unclear is how the phrase "without technological or personal assistance" would be applied to an activity that explicitly involves technological equipment (such as moving around with a wheelchair). The interpretation used in this article is that "moving around with a wheelchair" is the activity and that any technological or personal assistance would be added to (or removed from) that activity. In other words, if a person uses a wheelchair with active guidance from a smart wheelchair, then the activity is "moving around with a wheelchair" and "with or without technological assistance" refers to whether or not the wheelchair is providing active guidance. An alternative interpretation is that "without technological assistance" refers to both the active guidance and the wheelchair itself so that the activity "moving around with a wheelchair” when performed without technological assistance becomes "moving around without a wheelchair."
} 


\section{Will Need for Smart Wheelchairs Grow?}

The number of people who could benefit from a smart wheelchair, both in absolute numbers and as a percentage of the population, is likely to grow as the population of the United States ages. By 2030, the number of citizens over the age of 65 is expected to grow by 75 percent to 69 million people [99]. This increase is likely also to increase the number of individuals with age-related impairments and diagnoses, including visual impairment, dementia, and $\mathrm{AD}$. Advances in preventive care, medical treatments, and rehabilitation interventions may lower the percentage of older adults with disabilities. However, even under optimistic assumptions for longevity and disability, the number of older adults with ADL limitations will still be approximately 15 million, with nearly 3 million individuals with severe disability [99].

Within the population of U.S. veterans, several factors are likely to increase the number of individuals who would benefit from smart wheelchair technology. Veterans from the Korean and Vietnam conflicts are aging along with the rest of the U.S. population. Evidence of increased susceptibility to ALS and MS also exists among veterans of the first gulf war [100-102]. Finally, the incidence of polytrauma among veterans of Operation Iraqi Freedom and Operation Enduring Freedom is resulting in a cohort of veterans with multiple physical, cognitive, and perceptual impairments [103].

\section{CONCLUSIONS}

An estimated 2.3 million people aged 15 and older used a wheelchair or electric scooter in 1999 [104]. The projected population of smart powered wheelchair users of 1.4 to 2.1 million represents 61 to 91 percent of all wheelchair users. This projection does not mean, of course, that 61 to 91 percent of wheelchair users need a smart wheelchair all the time. It simply means that 61 to 91 percent of individuals would benefit from a smart wheelchair at least some of the time. The number of wheelchair users has grown at an average annual rate of 5.9 percent a year [104]. At that rate, by 2010, wheelchair users will increase to 4.3 million, with 2.6 million to 3.9 million of these users benefitting from a smart wheelchair. Much like cruise control or Global Positioning Systems in automobiles, which people use a fraction of the time they are driving, the capabilities of a smart wheelchair may initially be sold as a luxury for high-end wheelchairs and slowly move toward greater market penetration.

We believe that, eventually, estimations based on indirect assumptions about medical data will be replaced by direct information based on the ICF framework. As more researchers, epidemiologists, and demographers accept ICF, more and more data will be reported with the use of the ICF coding scheme. Eventually, the number of people who need smart wheelchairs (and many other advanced assistive technologies) will be determined directly from census data.

Smart wheelchairs have typically been considered a "niche" market, with a small potential user population that is limited to individuals with significant disabilities. We have argued, however, that a much larger number of wheelchair users could potentially benefit from smart wheelchair technologies. Investment in smart wheelchair research, therefore, has much greater potential impact than previously thought. Similarly, efforts to commercialize the smart wheelchair technology should be encouraged.

\section{ACKNOWLEDGMENTS}

This material was based on work supported by the National Science Foundation, grant EEEC-540865.

All three authors are working to commercialize smart wheelchair technology.

\section{REFERENCES}

1. Verburg G, Balfour L, Snell E, Naumann S. Mobility training in the home and school environment for persons with developmental delay. Final report. Toronto (Canada): Ontario Mental Health Foundation and Ministry of Community and Social Services' Research and Program Evaluation Unit; 1991.

2. Trefler E, Fitzgerald SG, Hobson DA, Bursick T, Joseph R. Outcomes of wheelchair systems intervention with residents of long-term care facilities. Assist Technol. 2004; 16(1):18-27. [PMID: 15357146]

3. Butler C. Effects of powered mobility on self-initiated behaviors of very young children with locomotor disability. Dev Med Child Neurol. 1986;28(3):325-32. [PMID: 2941328]

4. Finlayson M, Van Denend T. Experiencing the loss of mobility: perspectives of older adults with MS. Disabil Rehabil. 2003;25(20):1168-80. [PMID: 14534060] 
5. Pope AM, Tarlov AR. Disability in America: Toward a national agenda for prevention. Washington (DC): National Academy Press; 1991.

6. Iezzoni LI, McCarthy EP, Davis RB, Siebens H. Mobility difficulties are not only a problem of old age. J Gen Intern Med. 2001;16(4):235-43. [PMID: 11318924]

7. Fehr L, Langbein WE, Skaar SB. Adequacy of power wheelchair control interfaces for persons with severe disabilities: A clinical survey. J Rehabil Res Dev. 2000;37(3):353-60. [PMID: 10917267]

8. Simpson RC. Smart wheelchairs: A literature review. J Rehabil Res Dev. 2005;42(4):423-36. [PMID: 16320139]

9. United States Central Intelligence Agency. The world factbook. Washington (DC): Central Intelligence Agency; 2006.

10. Goedert M, Spillantini MG. A century of Alzheimer's disease. Science. 2006;314(5800):777-81. [PMID: 17082447]

11. Geldmacher DS, Whitehouse PJ Jr. Differential diagnosis of Alzheimer's disease. Neurology. 1997;48(5 Suppl 6):S2-9. [PMID: 9153154]

12. Brookmeyer R, Gray S, Kawas C. Projections of Alzheimer's disease in the United States and the public health impact of delaying disease onset. Am J Public Health. 1998; 88(9):1337-42. [PMID: 9736873]

13. Muò R, Schindler A, Vernero I, Schindler O, Ferrario E, Frisoni GB. Alzheimer's disease-associated disability: an ICF approach. Disabil Rehabil. 2005;27(23):1405-13. [PMID: 16418055]

14. Boillée S, Vande Velde C, Cleveland DW. ALS: a disease of motor neurons and their nonneuronal neighbors. Neuron. 2006;52(1):39-59. [PMID: 17015226]

15. Walling AD. Amyotrophic lateral sclerosis: Lou Gehrig's disease. Am Fam Physician. 1999;59(6):1489-96. [PMID: 10193591]

16. Trail M, Nelson N, Van JN, Appel SH, Lai EC. Wheelchair use by patients with amyotrophic lateral sclerosis: A survey of user characteristics and selection preferences. Arch Phys Med Rehabil. 2001;82(1):98-102.

[PMID: 11239293]

17. Czaplinski A, Yen AA, Simpson EP, Appel SH. Slower disease progression and prolonged survival in contemporary patients with amyotrophic lateral sclerosis: Is the natural history of amyotrophic lateral sclerosis changing? Arch Neurol. 2006;63(8):1139-43. [PMID: 16908741]

18. Krigger KW. Cerebral palsy: An overview. Am Fam Physician. 2006;73(1):91-100. [PMID: 16417071]

19. Palisano RJ, Hanna SE, Rosenbaum PL, Russell DJ, Walter SD, Wood EP, Raina PS, Galuppi BE. Validation of a model for gross motor function for children with cerebral palsy. Phys Ther. 2000;80(10):974-85.

[PMID: 11002433]
20. Bax M, Goldstein M, Rosenbaum P, Leviton A, Paneth N, Dan B, Jacobsson B, Damiano D. Proposed definition and classification of cerebral palsy. Dev Med Child Neurol. 2005;47(8):571-76. [PMID: 16108461]

21. Palisano RJ, Tieman BL, Walter SD, Bartlett DJ, Rosenbaum PL, Russell DJ, Hanna SE. Effect of environmental setting on mobility methods of children with cerebral palsy. Dev Med Child Neurol. 2003;45(2):113-20. [PMID: 12578237]

22. Sauerbeck L. Primary stroke prevention. Am J Nurs. 2006; 106(11):40-50. [PMID: 17068431]

23. Garber SL, Bunzel R, Monga TN. Wheelchair utilization and satisfaction following cerebral vascular accident. J Rehabil Res Dev. 2002;39(4):521-34. [PMID: 17638149]

24. Bowen A, McKenna K, Tallis RC. Reasons for variability in the reported rate of occurrence of unilateral spatial neglect after stroke. Stroke. 1999;30(6):1196-1202. [PMID: 10356099]

25. Hobart JC, Riazi A, Thompson AJ, Styles IM, Ingram W, Vickery PJ, Warner M, Fox PJ, Zajicek JP. Getting the measure of spasticity in multiple sclerosis: the Multiple Sclerosis Spasticity Scale (MSSS-88). Brain. 2006;129(Pt 1):224-34. [PMID: 16280352]

26. Jones SA, Shinton RA. Improving outcome in stroke patients with visual problems. Age Ageing. 2006;35(6): 560-65. [PMID: 16820528]

27. Seitz RJ, Freund HJ, Binkofski F. Motor dysfunction and recovery. In: Bogousslavsky J, editor. Long-term effects of stroke. New York (NY): Marcel Dekker; 2002. p. 105-47.

28. American Heart Association. Heart disease and stroke statistics - 2005 update. Dallas (TX): American Heart Association; 2005.

29. Lipson DM, Sangha H, Foley NC, Bhogal S, Pohani G, Teasell RW. Recovery from stroke: differences between subtypes. Int J Rehabil Res. 2005;28(4):303-8. [PMID: 16319555]

30. Singh R, Hunter J, Philip A, Todd I. Predicting those who will walk after rehabilitation in a specialist stroke unit. Clin Rehabil. 2006;20(2):149-52. [PMID: 16541935]

31. Fay BT, Boninger ML. The science behind mobility devices for individuals with multiple sclerosis. Med Eng Phys. 2002;24(6):375-83. [PMID: 12135646]

32. Woollard FA. The effect of mobility device use on strength, fatigue and quality of life in persons with multiple sclerosis [thesis]. Pittsburgh (PA): University of Pittsburgh, School of Health and Rehabilitation Sciences; 2005.

33. Piras MR, Magnano I, Canu ED, Paulus KS, Satta WM, Soddu A, Conti M, Achene A, Solinas G, Aiello I. Longitudinal study of cognitive dysfunction in multiple sclerosis: neuropsychological, neuroradiological, and neurophysiological findings. J Neurol Neurosurg Psychiatry. 2003; 74(7):878-85. [PMID: 12810771] 
34. Vollmer TL, Hadjimichael O, Preiningerova J, Ni W, Buenconsejo J. Disability and treatment patterns of multiple sclerosis patients in United States: A comparison of veterans and nonveterans. J Rehabil Res Dev. 2002;39(2):163-74. [PMID: 12051461]

35. Haddow LJ, Mumford C, Whittle IR. Stereotactic treatment of tremor due to multiple sclerosis. Neurosurg Q. 1997; 7(1):23-34.

36. Zifko UA, Rupp M, Schwarz S, Zipko HT, Maida EM. Modafinil in treatment of fatigue in multiple sclerosis. Results of an open-label study. J Neurol. 2002;249(8): 983-87. [PMID: 12195441]

37. Blake DJ, Bodine C. An overview of assistive technology for persons with multiple sclerosis. J Rehabil Res Dev. 2002;39(2):299-312. [PMID: 12051472]

38. Geser F, Seppi K, Stampfer-Kountchev M, Köllensperger M, Diem A, Ndayisaba JP, Ostergaard K, Dupont E, Cardozo A, Tolosa E, Abele M, Dodel R, Klockgether T, Ghorayeb I, Yekhlef F, Tison F, Daniels C, Kopper F, Deuschl G, Coelho M, Ferreira J, Rosa MM, Sampaio C, Bozi M, Schrag A, Hooker J, Kim H, Scaravilli T, Mathias CJ, Fowler C, Wood N, Quinn N, Widner H, Nilsson CF, Lindvall O, Schimke N, Eggert KM, Oertel W, Del Sorbo F, Carella F, Albanese A, Pellecchia MT, Barone P, Djaldetti R, Meco G, Colosimo C, Gonzalez-Mandly A, Berciano J, Gurevich T, Giladi N, Galitzky M, Ory F, Rascol O, Kamm C, Buerk K, Maass S, Gasser T, Poewe W, Wenning GK. The European Multiple System Atrophy-Study Group (EMSA-SG). J Neural Transm. 2005;112(12): 1677-86. [PMID: 16049636]

39. Gilman S, May SJ, Shults CW, Tanner CM, Kukull W, Lee VM, Masliah E, Low P, Sandroni P, Trojanowski JQ, Ozelius L, Foroud T. The North American Multiple System Atrophy Study Group. J Neural Transm. 2005;112(12): 1687-94. [PMID: 16284910]

40. Wenning GK, Tison F, Ben-Shlomo Y, Daniel SE, Quinn NP. Multiple system atrophy: a review of 203 pathologically proven cases. Mov Disord. 1997;12(2):133-47. [PMID: 9087971]

41. Vanacore N. Epidemiological evidence on multiple system atrophy. J Neural Transm. 2005;112(12):1605-12. [PMID: 16284906]

42. Watanabe H, Saito Y, Terao S, Ando T, Kachi T, Mukai E, Aiba I, Abe Y, Tamakoshi A, Doyu M, Hirayama M, Sobue G. Progression and prognosis in multiple system atrophy: an analysis of 230 Japanese patients. Brain. 2002;125(Pt 5): 1070-83. [PMID: 11960896]

43. Greenamyre J, Hastings T. Biomedicine. Parkinson'sdivergent causes, convergent mechanisms. Science. 2004; 304(5674):1120-22. [PMID: 15155938]
44. De Lau LM, Breteler MM. Epidemiology of Parkinson's disease. Lancet Neurol. 2006;5(6):525-35. [PMID: 16713924$]$

45. eMedicine [homepage on the Internet]. Omaha (NE): WebMD; c1996-2007 [updated 2007 May 17; 2007 Feb 8]. Gancher ST. Parkinson disease in young adults; [about 1 screen]. Available from: http://www.emedicine.com/neuro/topic635.htm

46. Worley SW, Kirby RL, MacLeod DA. Wheeling à petit pas: Parkinsonism detected by observation of wheelchair propulsion. Am J Phys Med Rehabil. 2006;85(11):931-34. [PMID: 17079968]

47. Zampieri C, Di Fabio RP. Progressive supranuclear palsy: disease profile and rehabilitation strategies. Phys Ther. 2006;86(6):870-80. [PMID: 16737412]

48. Pahwa R. Progressive supranuclear palsy. Med Clin North Am. 1999;83(2):369-79. [PMID: 10093583]

49. Burn DJ, Lees AJ. Progressive supranuclear palsy: where are we now? Lancet Neurol. 2002;1(6):359-69. [PMID: 12849397

50. Goetz CG, Leurgans S, Lang AE, Litvan I. Progression of gait, speech and swallowing deficits in progressive supranuclear palsy. Neurology. 2003;60(6):917-22.

[PMID: 12654953$]$

51. Teasdale G, Jennett B. Assessment of coma and impaired consciousness. A practical scale. Lancet. 1974;2(7872): 81-84. [PMID: 4136544$]$

52. Joint Committee on Injury Scaling: The Abbreviated Injury Scale, 1980 Revision. Des Plaines (IL): American Association for Automotive Medicine; 1980.

53. Avesani R, Salvi L, Rigoli G, Gambini MG. Reintegration after severe brain injury: a retrospective study. Brain Inj. 2005;19(11):933-39. [PMID: 16299934]

54. Hillier SL, Sharpe MH, Metzer J. Outcomes 5 years posttraumatic brain injury (with further reference to neurophysical impairment and disability). Brain Inj. 1997;11(9): 661-75. [PMID: 9376834]

55. Kersel DA, Marsh NV, Havill JH, Sleigh JW. Neuropsychological functioning during the year following severe traumatic brain injury. Brain Inj. 2001;15(4):283-96. [PMID: 11299130$]$

56. Masson F, Maurette P, Salmi LR, Dartigues JF, Vecsey J, Destaillats JM, Erny P. Prevalence of impairments 5 years after a head injury, and their relationship with disabilities and outcome. Brain Inj. 1996;10(7):487-97. [PMID: 8806009]

57. Masson F, Vecsey J, Salmi LR, Dartigues JF, Erny P, Maurette P. Disability and handicap 5 years after a head injury: a population-based study. J Clin Epidemiol. 1997; 50(5):595-601. [PMID: 9180652]

58. McKenna K, Cooke DM, Fleming J, Jefferson A, Ogden S. The incidence of visual perceptual impairment in patients 
with severe traumatic brain injury. Brain Inj. 2006;20(5): 507-18. [PMID: 16716997]

59. Thurman DJ. Traumatic brain injury in the United States: A report to Congress. Atlanta (GA): Centers for Disease Control and Prevention; 1999.

60. Bruns J Jr, Hauser WA. The epidemiology of traumatic brain injury: a review. Epilepsia. 2003;44 Suppl 10:2-10. [PMID: 14511388]

61. Gray DS. Slow-to-recover severe traumatic brain injury: a review of outcomes and rehabilitation effectiveness. Brain Inj. 2000;14(11):1003-14. [PMID: 11104140]

62. Langlois JA, Kegler SR, Butler JA, Gotsch KE, Johnson RL, Reichard AA, Webb KW, Coronado VG, Selassie AW, Thurman DJ. Traumatic brain injury-related hospital discharges. Results from a 14-state surveillance system, 1997. MMWR Surveill Summ. 2003;52(4):1-20. [PMID: 12836629]

63. Wyndaele $\mathrm{M}$, Wyndaele JJ. Incidence, prevalence and epidemiology of spinal cord injury: what learns a worldwide literature survey? Spinal Cord. 2006;44(9):523-29. [PMID: 16389270]

64. Nobunaga AI, Go BK, Karunas RB. Recent demographic and injury trends in people served by the Model Spinal Cord Injury Care Systems. Arch Phys Med Rehabil. 1999; 80(11):1372-82. [PMID: 10569430]

65. Burke DA, Linden RD, Zhang YP, Maiste AC, Shields $\mathrm{CB}$. Incidence rates and populations at risk for spinal cord injury: A regional study. Spinal Cord. 2001;39(5):274-78. [PMID: 11438844]

66. Grimes DA, Lang AE, Bergeron CB. Dementia as the most common presentation of cortical-basal ganglionic degeneration. Neurology. 1999;53(9):1969-74. [PMID: 10599767]

67. Jankovic J. Motor fluctuations and dyskinesias in Parkinson's disease: clinical manifestations. Mov Disord. 2005; 20 Suppl 11:S11-16. [PMID: 15822109]

68. Lebiedowska MK, Gaebler-Spira D, Burns RS, Fisk JR. Biomechanic characteristics of patients with spastic and dystonic hypertonia in cerebral palsy. Arch Phys Med Rehabil. 2004;85(6):875-80. [PMID: 15179639]

69. Albright AL, Barron WB, Fasick MP, Polinko P, Janosky J. Continuous intrathecal baclofen infusion for spasticity of cerebral origin. JAMA. 1993;270(20):2475-77. [PMID: 8230625]

70. Andersson C, Mattsson E. Adults with cerebral palsy: a survey describing problems, needs, and resources, with special emphasis on locomotion. Dev Med Child Neurol. 2001;43(2):76-82. [PMID: 11221908]

71. Sköld C, Levi R, Seiger A. Spasticity after traumatic spinal cord injury: nature, severity, and location. Arch Phys Med Rehabil. 1999;80(12):1548-57. [PMID: 10597805]
72. Alusi SH, Glickman S, Aziz TZ, Bain PG. Tremor in multiple sclerosis. J Neurol Neurosurg Psychiatry. 1999; 66(2):131-34. [PMID: 10071088]

73. Alusi SH, Worthington J, Glickman S, Bain PG. A study of tremor in multiple sclerosis. Brain. 2001;124(Pt 4):720-30. [PMID: 11287372]

74. Tefft D, Guerette P, Furumasu J. Cognitive predictors of young children's readiness for powered mobility. Dev Med Child Neurol. 1999;41(10):665-70. [PMID: 10587042]

75. Borson S, Raskind MA. Clinical features and pharmacologic treatment of behavioral symptoms of Alzheimer's disease. Neurology. 1997;48(5 Suppl 6):S17-24. [PMID: 9153156]

76. Baguley IJ, Cooper J, Felmingham K. Aggressive behavior following traumatic brain injury: how common is common? J Head Trauma Rehabil. 2006;21(1):45-56. [PMID: 16456391]

77. Busch RM, McBride A, Curtiss G, Vanderploeg RD. The components of executive functioning in traumatic brain injury. J Clin Exp Neuropsychol. 2005;27(8):1022-32. [PMID: 16207623]

78. Cicerone KD, Dahlberg C, Malec JF, Langenbahn DM, Felicetti T, Kneipp S, Ellmo W, Kalmar K, Giacino JT, Harley JP, Laatsch L, Morse PA, Catanese J. Evidencebased cognitive rehabilitation: updated review of the literature from 1998 through 2002. Arch Phys Med Rehabil. 2005;86(8):1681-92. [PMID: 16084827]

79. Rocchio C. Safe driving after brain injury. Family News and Views, Brain Injury Association of Oklahoma. 1998 Dec; Vol. 5, No. 7.

80. Boyle CA, Yeargin-Allsopp M, Doernberg NS, Holmgreen P, Murphy CC, Schendel DE. Prevalence of selected developmental disabilities in children 3-10 years of age: the Metropolitan Atlanta Developmental Disabilities Surveillance Program, 1991. MMWR CDC Surveill Summ. 1996; 45(2):1-14. [PMID: 8602136$]$

81. Ropacki SA, Jeste DV. Epidemiology of and risk factors for psychosis of Alzheimer's disease: a review of 55 studies published from 1990 to 2003. Am J Psychiatry. 2005; 162(11):2022-30. [PMID: 16263838]

82. Greenbaum MG, Fernandes S, Wainapel SF. Use of a motorized wheelchair in conjunction with a guide dog for the legally blind and physically disabled. Arch Phys Med Rehabil. 1998;79(2):216-17. [PMID: 9474006]

83. Pranghofer M. Wheels and white canes: Tips for helping blind wheelchair users. Braille Monitor. Baltimore (MD): National Federation for the Blind; 1996.

84. Royal National Institute for the Blind (RNIB). Guiding blind people who are wheelchair users. 2nd ed. London (England): RNlB; 2002.

85. Nath U, Ben-Shlomo Y, Thomson RG, Lees AJ, Burn DJ. Clinical features and natural history of progressive 
supranuclear palsy: a clinical cohort study. Neurology. 2003;60(6):910-16. [PMID: 12654952]

86. Driver J, Vuilleumier P. Perceptual awareness and its loss in unilateral neglect and extinction. Cognition. 2001; 79(1-2):39-88. [PMID: 11164023]

87. Mesulam MM. Spatial attention and neglect: parietal, frontal and cingulate contributions to the mental representation and attentional targeting of salient extrapersonal events. Philos Trans R Soc Lond B Biol Sci. 1999;354(1387): 1325-46. [PMID: 10466154]

88. Cooper RA, Fitzgerald SG, Boninger ML, Prins K, Rentschler AJ, Arva J, O'Connor TJ. Evaluation of a pushrimactivated, power-assisted wheelchair. Arch Phys Med Rehabil. 2001;82(5):702-8. [PMID: 11346854]

89. Simpson R, LoPresti E, Hayashi S, Guo S, Ding D, Ammer W, Sharma V, Cooper R. A prototype power assist wheelchair that provides for obstacle detection and avoidance for those with visual impairments. J Neuroeng Rehabil. 2005;2:30. [PMID: 16202136]

90. Cooper RA. Wheelchair selection and configuration. New York (NY): Demos Medical Publishing; 1998.

91. Katevas NL, Sgouros NM, Tzafestas SG, Papakonstantinou G, Beattie P, Bishop JM, Tsanakas P, Koutsouris D. The autonomous mobile robot SENARIO: A sensor aided intelligent navigation system for powered wheelchairs. IEEE Rob Autom Mag. 1997;4:60-70.

92. Pires G, Nunes U. A wheelchair steered through voice commands and assisted by a reactive fuzzy-logic controller. J Intell Rob Syst Theory Appl. 2002;34:301-14.

93. Kuno Y, Shimada N, Shirai Y. Look where you're going (robotic wheelchair). IEEE Rob Autom Mag. 2003;1:26-34.

94. Barea R, Boquete L, Mazo M, López E. System for assisted mobility using eye movements based on electrooculography. IEEE Trans Neural Syst Rehabil Eng. 2002;10(4):209-18. [PMID: 12611358]

95. Miller GE, Brown TE, Randolph WR. Voice controller for wheelchairs. Med Biol Eng Comput. 1985;23(6):597-600. [PMID: 4079489]
96. Simpson RC, Levine SP. Voice control of a powered wheelchair. IEEE Trans Neural Syst Rehabil Eng. 2002; 10(2):122-25. [PMID: 12236450]

97. Gao C, Hoffman I, Panzarella T, Spletzer J. ATRS-A technology-based solution to automobility for wheelchair users. Proceedings of the 6th International Conference on Field and Service Robotics. 2007 Jul 9-12; Chamonix, France.

98. International Classification of Functioning, Disability and Health: ICF. Geneva (Switzerland): World Health Organization; 2001.

99. Siegel JS. Aging into the 21st century. Bethesda (MD): National Aging Information Center, Administration on Aging; 1996.

100. Rose MR, Brix KA. Neurological disorders in Gulf War veterans. Philos Trans R Soc Lond B Biol Sci. 2006; 361(1468):605-18. [PMID: 16687265]

101. Haley RW. Excess incidence of ALS in young Gulf War veterans. Neurology. 2003;61(6):750-56. [PMID: 14504316]

102. Hallman WK, Kipen HM, Diefenbach M, Boyd K, Kang H, Leventhal H, Wartenberg D. Symptom patterns among Gulf War registry veterans. Am J Public Health. 2003; 93(4):624-30. [PMID: 12660208]

103. Sayer NA, Chiros CE, Sigford B, Scott S, Clothier B, Pickett T, Lew HL. Characteristics and rehabilitation outcomes among patients with blast and other injuries sustained during the Global War on Terror. Arch Phys Med Rehabil. 2008;89(1):163-70. [PMID: 18164349]

104. LaPlante MP. Demographics of wheeled mobility device users. In: Proceedings of the Conference on Space Requirements for Wheeled Mobility; 2003 Oct 9-11; Buffalo (NY). Buffalo (NY): University at Buffalo, State University of New York; 2003.

Submitted for publication January 29, 2007. Accepted in revised form July 24, 2007. 